\title{
A portable system for measuring cutaneous thresholds for warming and cooling
}

\author{
CLARE J FOWLER, * MARIAN B CARROLL, D BURNS,* N HOWE,* \\ KATHLEEN ROBINSON
}

From the Reta Lila Weston Institute of Neurological Studies, and The Interdepartmental Workshop, Middlesex Hospital Medical School, ${ }^{*}$ and Department of Clinical Neurophysiology, The National Hospital for Nervous Diseases, London, UK

SUMMARY Measurement of cutaneous thermal thresholds is a valuable technique for detecting small fibre neuropathy. A robust and portable microcomputer controlled system, which separately measures thresholds for warming and cooling, is described. Thresholds at three sites have been measured; the cheek, the dorsum of the hand and the sole of the foot. Regional variability and a correlation with age have been found, indicating the sensitivity of this system.

Psychophysical estimates of cutaneous thresholds for thermal sensation are now recognised as a valuable means of assessing small nerve fibre function. ${ }^{1-5}$ In mammalian peripheral nerve, small $(0 \cdot 5-6 \mu$ diameter) myelinated and unmyelinated nerve fibres are four times more numerous than the large $(7-13 \mu$ diameter) myelinated fibres. ${ }^{6}$ Disease of these small fibres is common in diabetes ${ }^{78}$ and is also a feature of some painful neuropathies, ${ }^{9}$ but stimulation and direct measurement of electrical responses in them is not possible under clinical conditions. Nerve conduction studies are therefore of limited diagnostic value in small fibre disease. Since cutaneous thermal sensations of cold are conveyed in the small myelinated fibres and sensations of warmth in the unmyelinated fibres, ${ }^{10}$ the integrity of each of these nerve fibre groups may be tested by psychophysical estimates of thresholds for thermal sensation.

Pure thermal stimuli can be conveniently given by means of thermoelectric modules in contact with the skin. First introduced in a device for physiological research, ${ }^{11}$ a thermoelectric module was then incorporated in the clinically used "Marstock" thermal testing system. ${ }^{1}$ In 1978 Dyck et $a l^{2}$ described a computer assisted method for measuring thresholds for cooling with a thermoelectric module, which measured both the temperature change and the amount of

\footnotetext{
Address for reprin! requests: Dr C J Fowler, Reta Lila Weston Institute of Neurological Studies, The Middlesex Hospital Medical School, London WIN 8AA, UK.
}

Received 10 October 1986. Accepted 16 December 1986 heat exchange the subject detects. The ingenious psychophysical testing routines and design concepts for computer controlled sensory testing devices introduced by those authors, have greatly influenced subsequent workers.

We describe a system which can measure thresholds for both warming and cooling. The testing routine employed is quick and easily performed by untrained subjects. Following each dynamic ramp of temperature change, spontaneous thermal reequilibration occurs, so that it has been possible to exclude the water cooling arrangements which other designs have incorporated. ${ }^{14}$ Thus our system has been made simple and portable.

We present here our results from a series of control subjects tested for both sensory modalities at three sites, the face, hand and foot.

\section{Method}

The system consists of the components shown in fig 1, all of which are portable.

(1) Computer The computer (Epson HX-20) is battery operated and has an integral 4 line screen, a microcasette drive and dot matrix printer. A single peripheral attachment, the thermode control unit, is connected to the computer through the RS232C port.

(2) Thermode control unit There are 3 functional components in this unit; a power supply (requiring mains connection), a board on which there is a temperature measuring circuit with an analogue-to-digital converter and a digitalto-analogue converter, and a front panel board with meters, lights and the connectors for the testing thermode.

(3) Thermode The working part of the thermode is made 


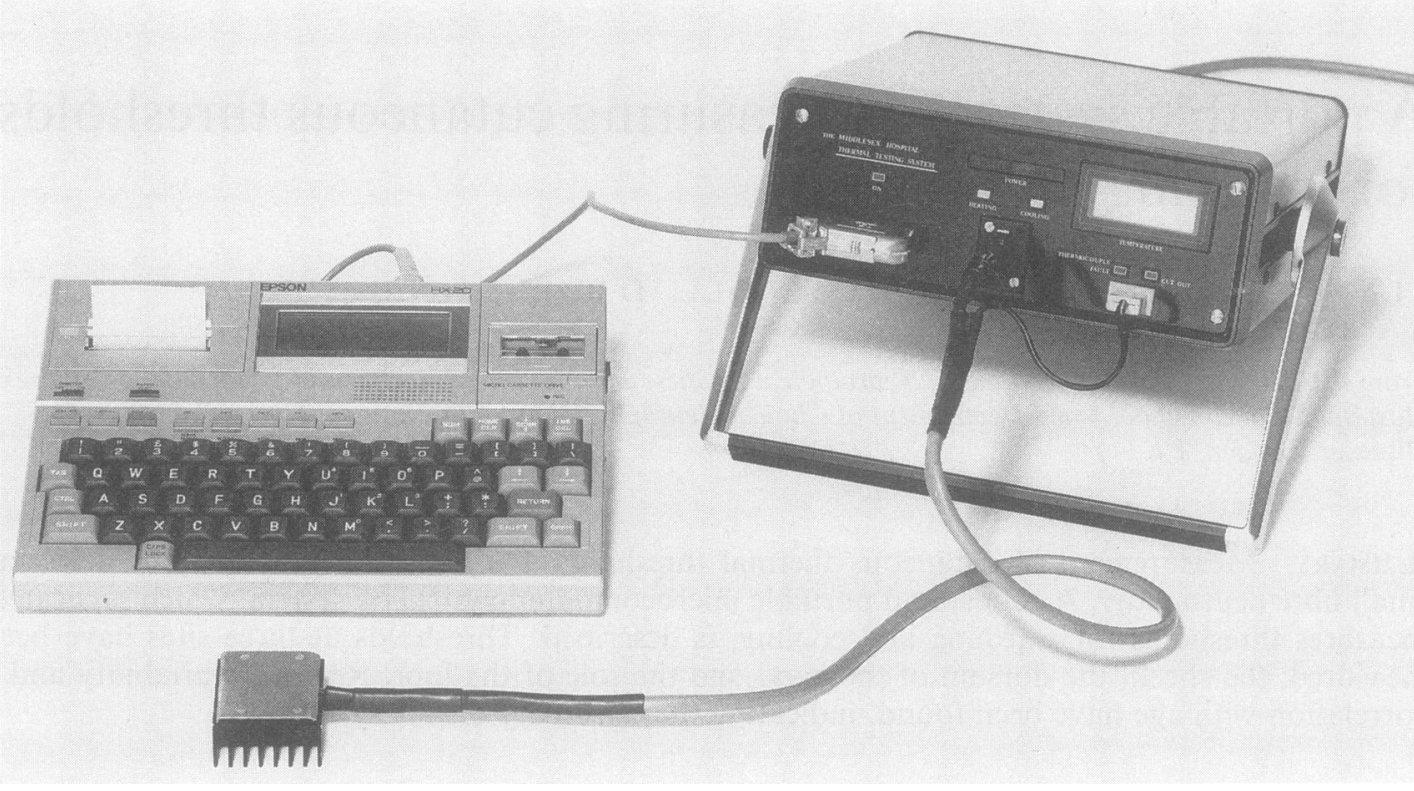

Fig 1 Thermal threshold measuring system.

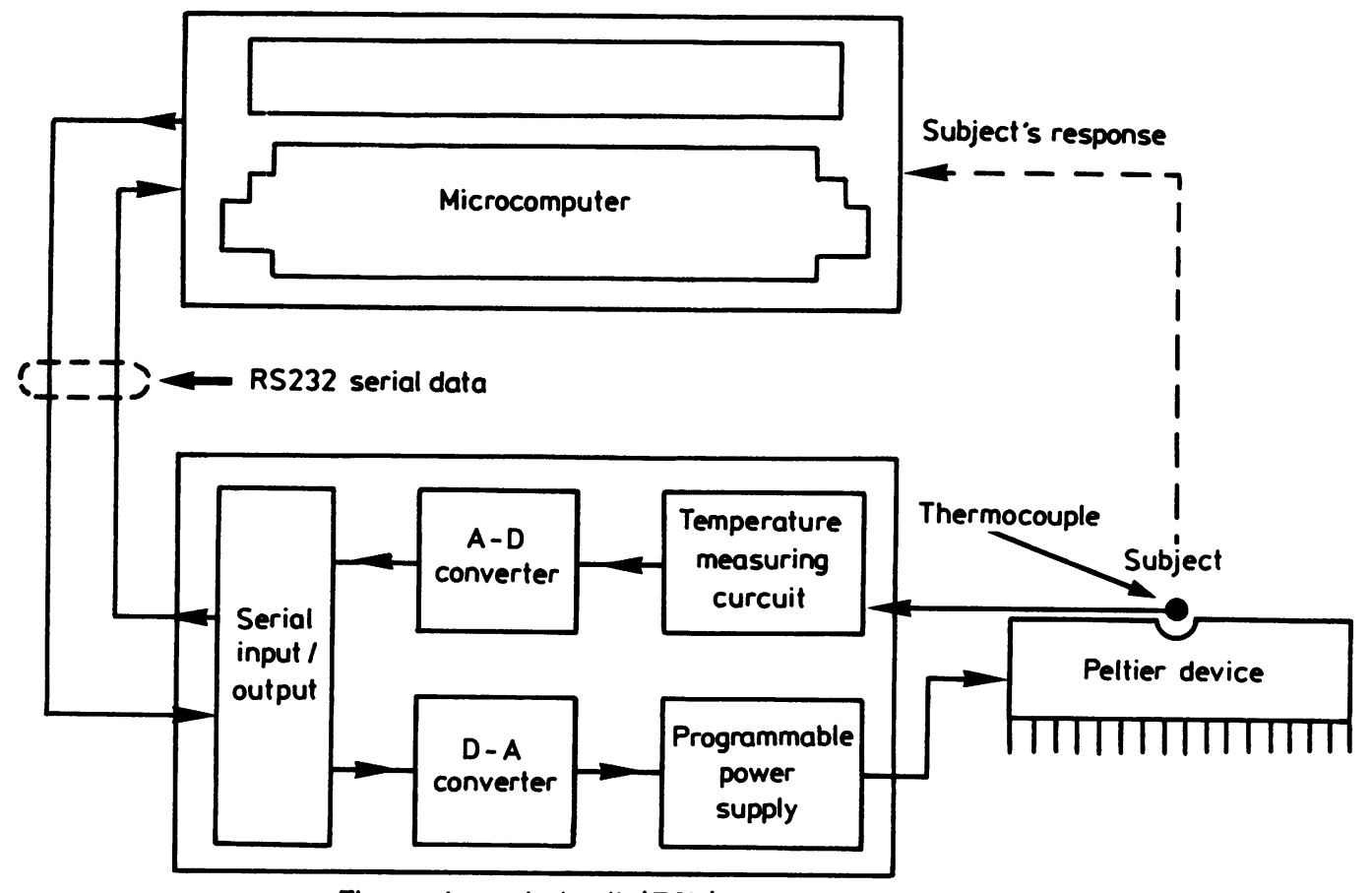

Thermode control unit (TCU) 


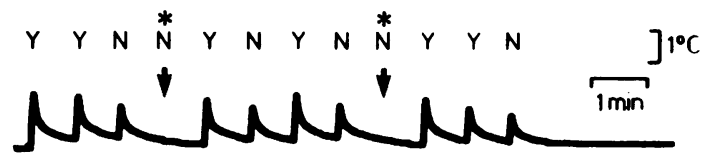

Fig 2 Example of the sequence of thermal stimuli and subject's responses during a test. "Catch trials" are marked with an asterisk. To prepare this figure the output from the thermocouple in the thermode was connected to a chart recorder.

from a commercially available thermoelectric module, which effects a temperature change according to the Peltier principle. This principle states that when current is passed through a bimetallic junction of dissimilar metals, cooling will occur on one side of the junction, and warming on the other, depending on the polarity of the current. In the thermode used here, a flat Peltier module is sandwiched between cooling fins and a thin $(1.6 \mathrm{~mm})$ copper plate. The contact testing area of thermode used on the face and the hand is 7.5 $\mathrm{cm}^{2}$ and that for the foot, $26 \mathrm{~cm}^{2}$ A thermocouple, embedded between the Peltier device and copper plate, connects to temperature measuring circuits in the thermode control unit.
Test stimuli take the form of discrete dynamic ramps of temperature change. The rate of temperature change is constant $\left(1^{\circ} \mathrm{C} / \mathrm{s}\right)$, so that the magnitude of each stimulus is determined by the time for which power is applied to the Peltier device. The duration, and thus intensity of stimuli, are organised in terms of "computer levels", as described by Dyck. ${ }^{2}$ The step intervals between intensity levels decrement geometrically by the square root of two.

\section{Test procedure}

Tests are performed in a warm room $\left(21-23^{\circ} \mathrm{C}\right)$ so that the subject is in a state of "thermal comfort" with sufficient vasodilatation of the extremities to avoid limb cooling. The polarity of the current can be set so that the device either heats or cools the skin, and thresholds for each are measured separately. The test is administered by an operator in response to prompts on the computer screen.

Following a warning tone emitted by the computer a dynamic thermal change occurs at the thermode/skin junction. The temperature change is calculated and recorded by the computer, in conjunction with the subject's response "yes/no" as to whether the stimulus was perceived. Following a ramp change of temperature, time elapses to permit natural re-equilibration of junction temperature. The time allowed for this is proportional to the magnitude of the preceding ramp (fig 2).

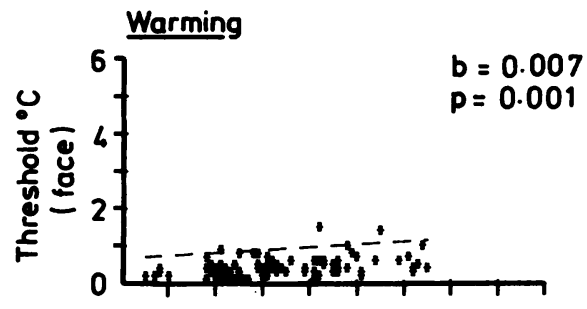

\section{Cooling}
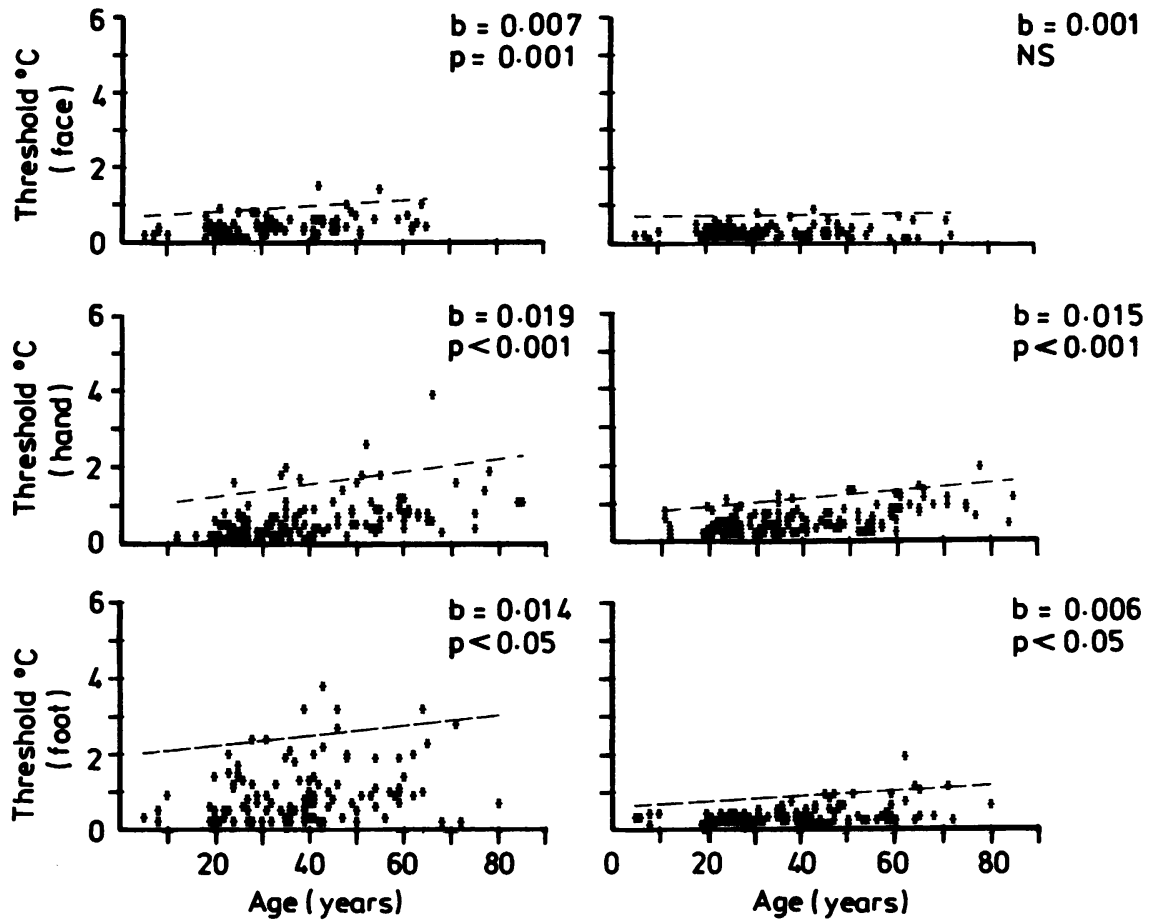

Fig 3 Graphs showing thresholds for three sites measured in control subjects. Note that the contact area of the thermode used on the face and the hand was $7.5 \mathrm{~cm}^{2}$, whereas that on the foot was $26 \mathrm{~cm}^{2}$. 
An approximate value for threshold is established first. The estimate at this stage, determines whether the subject should subsequently be given stimuli from a range appropriate for ordinary sensitivity, or from a higher range.

An accurate measure of threshold is then made. Starting at a level well above the approximately estimated threshold, the subject receives a series of discrete dynamic thermal ramps. If the subject responds "yes" to a stimulus, the next stimulus intensity is reduced by one step level; following a response "no", the intensity is increased. The test terminates when four "nos" have been given. This usually requires 9-15 stimuli and takes between 5-10 minutes. Interspersed at random intervals are "catch trials" which are used to assess the subject's reliability (fig 2).

Threshold is taken as mid-point between the mean of values for which the subject has said "yes" following the first "no" and the mean of stimuli for which "no" (non-catch) was given. Various conditions have been written into the program to allow for treatment of special circumstances, eg: unreliable or inconsistent responses.

Control subjects for these studies were hospital staff and their associates, who were in good general health.

The data were analysed using the statistical package "Minitab".

\section{Results}

\section{Control subjects}

The greatest number of subjects studied was for measurements on the hand; a total of 209, 106 males, mean age $41.8 \mathrm{yr}(\mathrm{SD}=19.4)$ and 103 females, mean age $37.4(\mathrm{SD}=16 \cdot 6)$. Of these 71 males and $72 \mathrm{fe}-$ males had both warming and cooling tests. Measurements were made from 116 subjects on the foot and 76 on the face. The sex and age distribution of subjects in these smaller groups were similar to that of the group examined for the hand data.

\section{Cutaneous thresholds}

1. Sensitivity to age The effect of age on cutaneous threshold was analysed using least squares regression methods. Examination of the residuals obtained from the regression analysis showed that the simple regression formula $(y=a+b x)$ provided the best fit to the data. The effect of age on warming threshold was statistically significant at all the sites tested. The effect of age on cooling threshold was significant for the hand and foot only. The regression coefficient (b) and significance levels (p) are shown in fig 3, together with confidence intervals based on 2 standard deviations.

2. Junction temperature The skin temperature beneath the thermode, "junction temperature" was recorded at the end of each test. Linear regression analysis was carried out to determine whether junction temperature and cutaneous thresholds were related. The regression coefficients of either modality at esci ste. failed to show any effect of junction temperaiture on threshold.

3. Warming-cooling threshold difference Many sub- jects commented after the tests that warming was very much more difficult to judge than cooling. Cooling is an abrupt sensation, whereas gentle warming has pleasant but subtle qualities. Paired $t$ tests were used to determine whether threshold for warming was significantly different from threshold for cooling in an individual. The difference was significant for data from the foot and face. Eighty seven per cent and $71 \%$ respectively had warming thresholds greater than cooling. There was no significant difference between warming and cooling thresholds on the hand.

\section{Discussion}

The results show that thresholds are independent of limb temperature within the range of naturally occurring values of control subjects in a state of "thermal comfort". Water cooling of the thermode is not necessary since re-equilibration of the skin-thermode junction temperature under natural conditions is adequate (fig 2). Re-equilibration of the junction temperature results from heat dissipation from the cooling fins of the thermode and by absorption into the heat sink capacity of the cutaneous vascular system, which provides a convenient physiological heat pump maintaining a constant temperature at the test site. By avoiding integral water cooling, it has been possible to keep the apparatus compact and portable.

As with all psychophysical tests, the concentration and cooperation of the subject is critical. Testing protocols based on that of Dyck et al, ${ }^{2-4}$ impose "forced choice" decision whereby the subject must decide in which of two presentations a stimulus wasdetected. Although forced choice is ideally suited to demonstrating subtle changes of thresholds in laboratory subjects, patients are reluctant to have to answer clinical tests by guessing when stimuli are below threshold levels of intensity. Such methods are inevitably longer than that used here, which simply asks the naive subject to respond "yes" or "no" to each stimulus.

Preliminary studies showed that sensitivity of the foot in control subjects was very much less than that of the hand. However, it was possible to lower the figure of threshold for the foot into the optimal functioning range of the system, by increasing the contact area of the thermode. This is due to the effect of spatial summation in the perception of thermal stimuli. For testing the sole of the foot, the thermode is approximately three times the size of that used on the hand or face. Being able to test the sole of the foot is particularly advantageous, since in many length dependent neuropathies, abnormalities could be expected to be found here before any other site. This is particularly important in diabetics when sensory loss on the sole may be complete, although there is some 
preservation of pain sensation on the dorsum of the foot. ${ }^{12}$

Measurement of cutaneous thermal thresholds offers an easy means, albeit subjective, of assessing the integrity of small myelinated fibres (cooling) and unmyelinated fibres (warming). This portable system can be readily used in diabetic clinics with a special interest in problems related to small fibre dysfunction, such as foot ulceration and neurogenic impotence. $A$ correlation between age and threshold indicates that subtle differences can be measured. The demonstrated sensitivity of this system makes it suitable for quantitating sensation in clinical trials. The method is also a useful adjunct in clinical neurophysiological practice for assessment of small nerve fibre function in painful neuropathic conditions where nerve conduction studies may be normal.

We acknowledge with thanks, helpful discussions with Mr G Fowler, Mr A Baldwin, Dr R Hellon, Dr PM le Quesne, Dr N Murray, Dr P Nathan, and Dr RG Willison. We are grateful to Dr M Harrison for support and encouragement. The work was funded in part by a grant from the Sir Jules Thorn Charitable Trust. Ms M Carroll's collaboration in this study was made possible by a grant from Imperial Chemical Industries PLC.

This system was demonstrated at the XIth International Congress of Electroencephalography and Clinical Neurophysiology, London UK," August 1985.

\section{References}

I Fruhstorfer H, Lindblom U, Schmidt WG. Method for quantitative estimation of thermal thresholds in patients. $J$ Neurol Neurosurg Psychiatry 1976;39:1071-5.

2 Dyck PJ, Karnes J, O'Brian PC, Zimmerman IR. Detection thresholds of cutaneous sensation in humans. In: Dyck PJ, Thomas PK, Lambert E, Bunge R, eds. Peripheral Neuropathy. Philadelphia: Saunders, 1984:1103-38.

3 Bertelsmann FW, Heimans JJ, Weber EJM, et al. Thermal discrimination thresholds in normal subjects and patients with diabetic neuropathy. $J$ Neurol Neurosurg Psychiatry 1985;48:686-90.

4 Jamal GA, Hansen S, Weir AJ, Ballantyne JP. An improved automated method for the measurement of thermal thresholds. 1. Normal subjects. J Neurol Neurosurg Psychiatry 1985;48:354-60.

5 Arezzo JC, Schaumburg HH, Laudadio C. Thermal sensitivity tester. Diabetes 1986;35(5):590-2.

6 Ochoa J, Mair WGP. The normal sural nerve in man. Acta Neuropathol 1969;13:197-216.

7 Guy RJC, Clark CA, Malcolm PN, Watkins PJ. Evaluation of thermal and vibration sensation in diabetic neuropathy. Diabetologia 1985;28:131-7.

8 Heimans JJ, Bertelsmann FW, Van Rooy JCGM. Large and small fiber function in painful diabetic neuropathy. J Neurol Sci 1986;74:1:1-9.

9 Scadding JW. Peripheral neuropathy. In: Wall PD, Melzack R, eds. Textbook of Pain. London: Churchill Livingstone, 1984:413-25.

10 Lindblom U. Quantitative testing of sensibility including pain. In: Stalberg E, Young R, eds. Clinical Neurophysiology. London: Butterworths, 1980:169-90.

11 Kenshalo DR, Bergen DC. A device to measure cutaneous temperature sensitivity in humans and subhuman species. J Appl Physiol 1975;39:1038-40.

12 Le Quesne PM, Fowler CJ. A study of pain thresholds in diabetics with neuropathic foot lesions. J Neurol Neurosurg Psychiatry 1986;49:119-24. 